\title{
SINKRONISASI RENCANA UMUM TATA RUANG WILAYAH PERTAHANAN DENGAN PETA ZONA RUANG RAWAN BENCANA DI KOTA PALU, SIGI, DAN DONGGALA
}

\author{
Oleh:

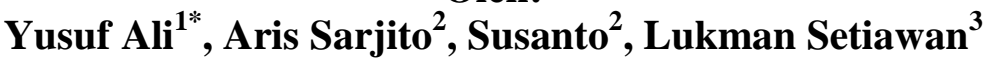 \\ Email : yusufali8788@gmail.com \\ ${ }^{1,2}$ Universitas Pertahanan Republik Indonesia \\ ${ }^{3}$ Universitas Bosowa
}

\begin{abstract}
ABSTRAK
Bencana alam merupakan salah satu ancaman nyata bagi pertahanan dan keamanan Negara Kesatuan Republik Indonesia, sehingga perlu dipertimbangkan dalam segala aspek pembangunan fasilitas pertahanan negara. Penelitian ini bertujuan untuk menganalisis tentang sinkronisasi rencana umum tata ruang wilayah pertahanan dengan peta zona ruang rawan bencana di Kota Palu, Sigi, Donggala dalam rangka mendukung pertahanan dan keamanan negara. Penelitian ini merupakan penelitian kualitatif yang dilakukan melalui kegiatan observasi langsung dan wawancara terhadap beberapa narasumber terkait, serta studi pustaka terhadap dokumen pendukung yang relevan dengan fokus penelitian. Data yang diperoleh kemudian dianalisis menggunakan model analisis data kualitatif. Berdasarkan hasil analisis data, diperoleh hasil bahwa Peta Zona Ruang Rawan Bencana untuk wilayah Kota Palu dan sekitarnya telah di buat untuk di pedomani dalam pembangunan di wilayah tersebut. Pada peta tersebut, fasilitas militer termasuk dalam kelas resiko sangat tinggi, sehingga dalam pembuatan rencana tata ruang wilayah pertahanan di wilayah Palu, Sigi, dan Donggala, baik itu perbaikan fasilitas/pangkalan militer yang mengalami kerusakan akibat bencana gempa dan tsunami, maupun pembangunan fasilitas/pangkalan militer yang baru, harus didasarkan pada Peta Zona Ruang Rawan Bencana. Hal ini perlu dilaksanakan sebagai upaya sinkronisasi antara Peta Zona Ruang Rawan Bencana dengan Rencana Tata Ruang Wilayah Pertahanan di wilayah Palu, Sigi, dan Donggala agar kejadian kerusakan terhadap fasilitas militer strategis, seperti dermaga kapal selam dan kapal perang di Lanal Palu, akibat bencana gempa bumi dan tsunami tidak terulang kembali di masa depan. Peneliti merekomendasikan kepada pemerintah dan instansi terkait agar senantiasa meningkatkan sinergitas antara TNI dan pemerintah daerah, serta organisasi lainnya dalam proses penanggulangan bencana dan pembangunan kembali fasilitas yang rusak akibat bencana. Proses perencanaan dan pembangunan fasilitas/pangkalan militer tersebut juga harus di sinkronkan dengan peta ruang rawan bencana, sehingga dapat mencegah terganggunya kesiapan Alutsista dalam rangka Pertahanan Negara di masa depan.
\end{abstract}

Kata Kunci: Bencana Alam, Gempa, Liquifaksi, Tsunami, Rencana Tata Ruang Wilayah Pertahanan, Zona Ruang Rawan Bencana.

\section{A. PENDAHULUAN}

Salah satu syarat utama terbentuknya suatu negara adalah wilayah geografis. Sehingga pengelolaan potensi yang dimiliki oleh wilayah geografis suatu negara menjadi sangat penting untuk diperhatikan. Potensi yang dimaksud dalam hal ini adalah bentang 
lahan, geologi tanah, hidrologi, iklim, flora dan fauna yang harus dikelola penggunaannya. Pemanfaatan potensi lahan tidak hanya digunakan untuk memenuhi kebutuhan hidup masyarakat, tapi juga sangat berperan besar bagi kedaulatan negara. Hal ini tercantum di dalam Undang-Undang Republik Indonesia No. 26 tahun 2007 tentang Penataan Ruang pasal 1 ayat 28. Oleh sebab itu keberadaan sumber daya lahan digunakan juga dalam Sistem Pertahanan Semesta yang tercantum di dalam Undang-Undang Republik Indonesia No. 3 tahun 2002, pasal 1 ayat 2 tentang Pertahanan Negara. Hal ini bertujuan untuk membina Ruang Alat dan Kondisi Juang (RAK JUANG) yang dapat diartikan sebagai lahan dan tanah yang harus dikelola di dalam Rencana Umum Tata Ruang Wilayah Pertahanan (RUTR Wilhan) yang mengatur kepemilikan lahan untuk pertahanan (Defense Estate). Kepemilikan lahan untuk pertahanan digunakan sebagai daerah pelatihan, instalasi dan perkantoran serta asrama, gudang munisi daerah dan pusat, serta daerah penembakan rudal.

Dalam ilmu manajemen pertahanan dibahas pula tentang pembangunan Instalasi militer yang direncanakan melalui Rencana Umum Tata Ruang
Pertahanan. Proses pembangunan tersebut tentunya harus memperhatikan beberapa ancaman yang dapat menghambat kesiapan bahkan dapat menghentikan operasional kegiatan bidang pertahanan. Salah satu ancaman yang dimaksud tersebut adalah bencana alam. Di Indonesia, ancaman bencana alam merupakan salah satu ancaman yang sangat nyata dan telah banyak menimbulkan korban, baik korban jiwa, harta benda hingga dapat menyebabkan kehancuran terhadap instalasi militer yang berada di daerah bencana tersebut.

Bencana alam yang yang pernah terjadi di Indonesia antara lain adalah Gempa Bumi dan Tsunami di Aceh pada tahun 2004; Gempa Bumi di Nias pada tahun 2005; Gempa Bumi di Yogyakarta tahun 2006; Tsunami di Pangandaran tahun 2006; Gempa Bumi di Padang, Sumatera Barat tahun 2007 dan 2009; Gempa Bumi di Tasikmalaya, Jawa Barat tahun 2009 (Malik, 2009); Gempa Bumi dan Tsunami di Mentawai 2010; Gempa Bumi di Pidie Jaya tahun 2016; Gempa Bumi di Lombok tahun 2018, Gempa Bumi dan Tsunami di Palu dan Donggala tahun 2018; dan Tsunami Banten dan Lampung tahun 2018 (DIBI, 2019). Bencana alam tersebut memberikan dampak kerusakan dan kerugian dalam 
jumlah besar, baik materi maupun korban jiwa.

Salah satu bencana alam terbesar dan terbaru, serta menimbulkan kerusakan pada instansi militer yang ada di Indonesia adalah bencana tsunami yang terjadi di Kota Palu. Secara geografis, Kota Palu menjadi wilayah Patahan Palu Koro dengan slip-rate jangka panjang sebesar $40 \mathrm{~mm}-50 \mathrm{~mm}$ per tahun serta pertemuan dengan Patahan Matano yang menyebabkan pergerakan aktif utama di wilayah Sulawesi Tengah (Bellier, et. al., 2001). Hingga saat ini, Kota Palu yang dilintasi oleh Patahan Palu Koro telah mengalami gempa bumi yang merusak. Kota Palu memiliki berbagai kondisi geologis dan endapan aluvial yang berasal dari batuan kuarter aluvium yang masih muda. Tanah lapisan atas (1-7 m) terutama bertekstur pasir, lempung di lapisan tengah, dan liat di lapisan bawah. Peta muka air tanah menunjukkan air tanah yang dangkal di daerah tesebut (Minasny, et al. 2020). Kondisi ini dapat dilihat pada gambar berikut:

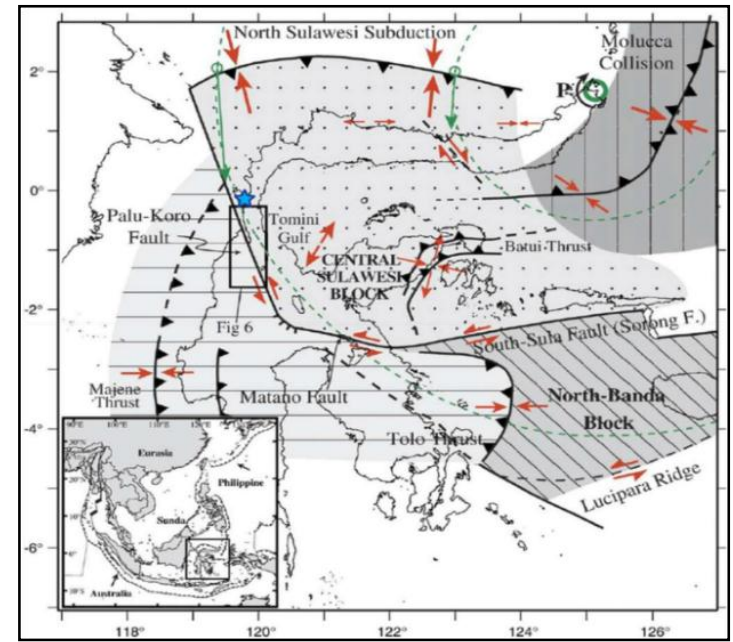

Gambar 1. Faults of Sulawesi

(Sumber: Build Change, 2019)

Pada tanggal 29 September 2018 terjadi gempa bumi dengan Magnitudo 7,4 SR yang menyebabkan kerusakan parah pada pantai padat penduduk di Kota Palu. Selain itu, gempa bumi tersebut juga disusul oleh terjadinya peristiwa tsunami yang semakin memperparah keadaan di kota Palu. Diantara beberapa gelombang tsunami yang tiba di kota, dua bentuk gelombang awal kemungkinan besar dihasilkan oleh tanah longsor di pantai Barat Daya Teluk Palu, sekitar 5 km dari salah satu pusat perbelanjaan. Kejadian tersebut menunjukan bahwa gelombang tsunami yang menghantam garis pantai terdekat beberapa menit setelah gempa bumi.

Kemungkinan tsunami yang disebabkan tanah longsor dicurigai oleh banyak peneliti yang percaya bahwa efek coseismic saja tidak dapat menjelaskan 
pergerakan massa air yang masif. Tanah longsor merupakan mekanisme terpenting kedua dari tsunami setelah gempa bumi. Tsunami yang dihasilkan oleh tanah longsor sering terjadi di teluk yang sempit dan menghasilkan amplitudo gelombang yang signifikan serta dapat diperkuat dengan memfokuskan energi dan resonansi (Harbitz et al. 2006). Berikut adalah gambaran dan informasi bencana tsunami di teluk palu:

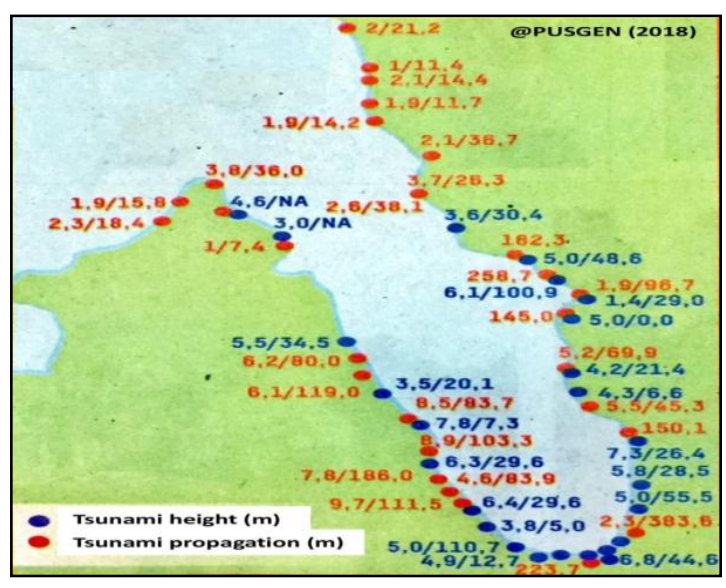

Gambar 2. Tsunami Height and Propagation

(Sumber: Pusat Studi Gempa Nasional, 2018)

Dari data yang dicatat oleh BNPB hingga dengan tanggal 12 Oktober 2018, diketahui bahwa dampak bencana tsunami yang terjadi tersebut telah menimbulkan korban jiwa sebanyak 2.010 orang, korban luka-luka sebanyak 10.679 orang, sebanyak 82.775 orang mengungsi, dan 67.310 rumah rusak dan diperkirakan masih 671 orang dinyatakan hilang.
Selain korban jiwa, gelombang tsunami yang terjadi tersebut juga menyebabkan kerusakan parah pada beberapa instalasi militer terutama yang berada di sekitar pantai (Yusuf Ali, et al. 2019). Kerusakan pada instalasi militer di Kota Palu tersebut dapat dilihat pada gambar dibawah ini:

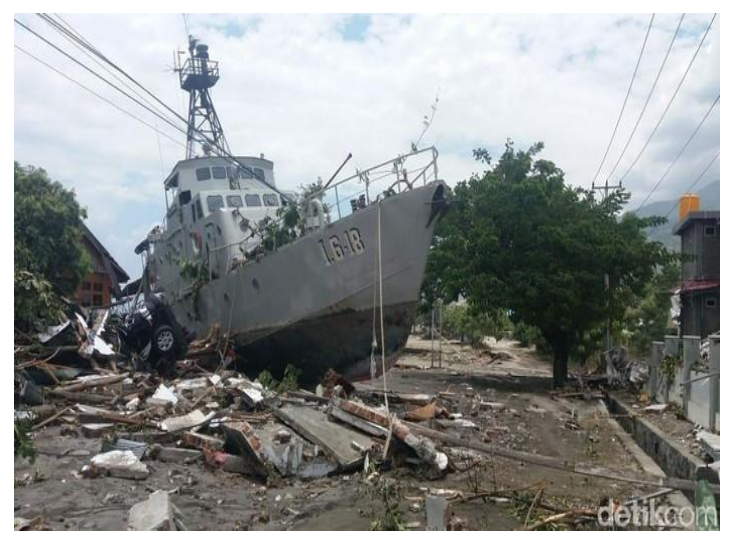

Gambar 3. Kondisi Dermaga Lanal Palu setelah terjadi Tsunami (Sumber: DetikNews, 2018)

Berdasarkan Peraturan Pemerintah Nomor 21 Tahun 2008 tentang Penyelenggaraan Penanggulangan Bencana, mitigasi bencana adalah serangkaian upaya untuk mengurangi risiko bencana, baik melalui pembangunan fisik maupun penyadaran dan peningkatan kemampuan menghadapi ancaman. Akan tetapi, proses perencanaan fisik perkotaan dan wilayah di Indonesia belum sepenuhnya bertitik tolak pada kerawanan bencana alam. Identifikasi kerawanan bencana dan lingkungan menjadi hal yang penting dan keharusan dalam kegiatan perencanaan sebagai 
usaha untuk memperkecil dan mengurangi dampak yang ditimbulkan oleh bencana. Oleh karena itu, diperlukan pertimbangan yang bijaksana dalam pengambilan keputusan karena mitigasi bertujuan mengurangi atau menghilangkan risiko bencana pada kawasan-kawasan strategis yang berpotensi risiko tinggi jika terjadi bencana (Edyanto, 2011).

Untuk mengurangi resiko bencana yang kemungkinan bisa terjadi lagi di Wilayah Palu dan sekitarnya, maka dilaksanakan penyusunan peta zona ruang rawan bencana untuk Palu dan sekitarnya. Peta zona ruang rawan bencana (ZRB) merupakan pedoman pemanfaatan ruang berdasarkan kerentanan bencana. Saat ini peta tersebut dijadikan acuan untuk merevisi Rencana Tata Ruang Wilayah (RTRW) Kota Palu dan sekitarnya. Peta itu dirancang lima kementerian dan lembaga, yakni Badan Perencanaan Pembangunan Nasional (Bappenas), Kementerian Agraria dan Tata Ruang/Badan Pertanahan Nasional (ATR/BPN), Kementerian Pekerjaan Umum dan Perumahan Rakyat (PUPR), Kementerian Energi dan Sumber Daya Mineral, serta Badan Meteorologi, Klimatologi, dan Geofisika (BMKG), tetapi peta ZRB yang di tanda tangani pada tanggal 11 Desember 2018 di Kantor
Wakil Presiden tersebut masih mungkin akan berubah karena menurut BMKG peta ZRB tersebut tidak menyertakan survey kerentanan gempa dan likuefeksi BMKG (Kompas, 2020).

Sementara itu alat utama system senjata (Alutsista) berupa kapal selam Alugoro-504 yang merupakan kapal selam produk pertama rakitan PT PAL dan Korea Selatan dalam tahap penyelesaian pembangunannya, dan akan memperkuat kebijakan pengembangan Alutsista. Kapal selam tersebut nantinya akan sangat membutuhkan pangkalan, sementara saat ini pangkalan kapal selam yang ada di Lanal Palu rentan terhadap resiko bencana alam yang mungkin masih mengancam di Palu, Sigi, dan Donggala (Pasigala). Selain itu Bandar Udara SiS Al Jufri yang ada di Kota Palu juga mengalami kerusakan cukup parah saat terjadi bencana, padahal bandara tersebut juga digunakan oleh pesawat militer (Pertahanan). Demikian pula dengan beberapa pangkalan milik kesatuan Angkatan Darat terdampak pula oleh bencana alam yang terjadi di Pasigala. Berdasarkan permasalahan diatas, maka peneliti tertarik untuk meneliti tentang sinkronisasi antara rencana umum tata ruang wilayah pertahanan dengan peta zona rawan bencana di Kota Palu, Sigi, 
dan Donggala. Hasil penelitian ini diharapkan mampu memberikan masukan dan rekomendasi tentang pentingnya sinkronisasi rencana tata ruang wilayah pertahanan dengan peta zona ruang rawan bencana, terutama di daerah yang rawan terjadi bencana.

\section{B. METODE PENELITIAN}

Penelitian ini merupakan penelitian kualitatif yang banyak mengambil data berupa kata-kata dan kegiatan orang atau kelompok orang, serta dokumen-dokumen pendukung berupa catatan, dokumen administrasi, photo dan lainnya sebagai data pendukung (Creswell, 2010). Subyek penelitian ini adalah para informan/narasumber yang berkaitan langsung dengan sinkronisasi rencana tata ruang wilayah pertahanan dengan peta zona ruang rawan bencana di Pasigala yang terdiri atas: Dirjen Renhan Kemhan, Asrena Panglima TNI, Asrena Kasal, Danrem 132/Tadulako, Dan Lanal Palu, Walikota Palu, Bupati Kabupaten Sigi Biromaru, Komandan Kodim Donggala, Bupati Kabupaten Donggala, Tokoh Masyarakat di Palu, Sigi, dan Donggala, Ka Bappeda Palu, Sigi, Donggala, Ka Kan Wilhan Prov. Sulteng dan Ka Kan BMKG Palu.

Data primer pada penelitian ini diperoleh melalui kegiatan wawancara, observasi dan focus group discussion. Sedangkan data sekunder diperoleh melalui kegiatan studi pustaka dan pengambilan dokumen pendukung lainnya yang relevan dengan fokus penelitian. Selanjutnya, data yang diperoleh dianalisis menggunakan model analisis data kualitatif, yang meliputi: kondensasi data (data condensation), penyajian data (data display), dan penarikan kesimpulan atau verifikasi (conclusion/veryfing) (Miles dan Huberman, et al, 2014).

\section{HASIL DAN PEMBAHASAN}

Berdasarkan hasil wawancara dengan Bapak Lukman dari BPBD Provinsi Sulawesi Tengah pada tanggal 20 Agustus 2020 di Kota Palu, di peroleh keterangan bahwa pada tahun 2018 sudah dibuat Peta Zona Ruang Rawan Bencana untuk Kota Palu, Sigi dan Donggala, yang dibuat oleh Badan Geologi Kementerian Energi dan Sumber Daya Mineral beserta Tim. Selanjutnya Peta Ruang Rawan Bencana ini digunakan untuk Peta Geologi Tata Lingkungan Untuk Penataan Ruang Palu, Sigi, Donggala Provinsi Sulawesi Tengah.

Walaupun pihak Kemhan/TNI tidak ikut sebagai pihak yang menandatangani Peta Zona Ruang Rawan Bencana untuk Palu, Sigi, Donggala, tetapi dalam 
pelaksanaan penataan ruang untuk diwilayah ini, sebaiknya mengacu kepada pembangunan pangkalan militer Peta tersebut.

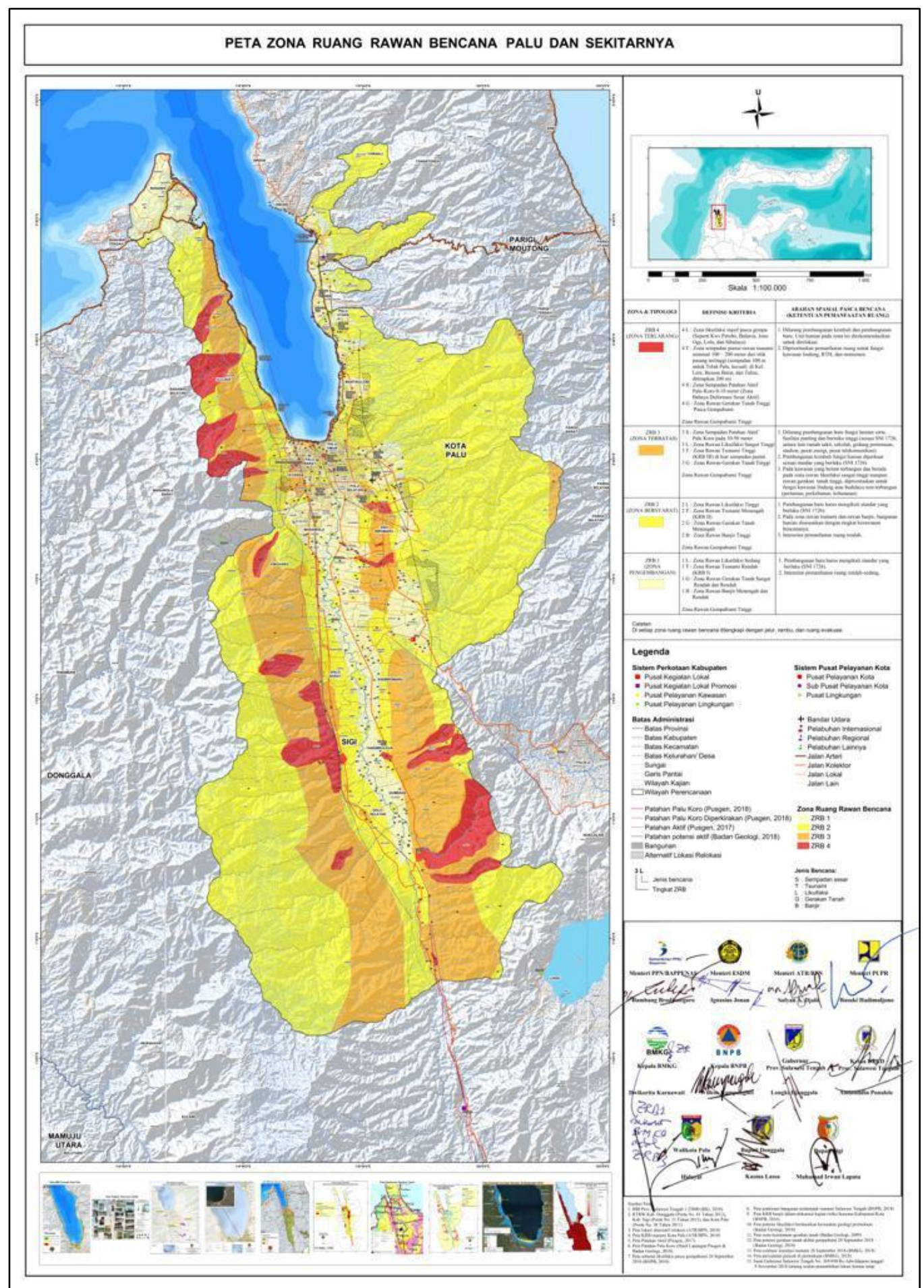

Gambar 4. Peta Zona Ruang Rawan Bencana Kota Palu, Sigi dan Donggala (Sumber: Badan Geologi Kementerian ESDM, 2018) 
Namun pada kenyataannya, pada saat penyusunan peta zona ruang rawan bencana untuk Kota Palu dan sekitarnya, terjadi sedikit polemik, karena para pihak yang menanda tangani peta tersebut masih belum lengkap, yaitu belum ada tanda tangan dari Kepala BMKG, sementara pihak yang lain menanda tangani, antara lain: Menteri PPN/BAPPENAS, Menteri ESDM, Menteri ATR/BPN, Menteri PUPR, Kepala BNPB, Gubernur Provinsi Sulawesi Tengah, Kepala DPRD ProvinsiSulawesi Tengah, Walikota Palu, Bupati Donggala, Bupati Sigi. Dari informasi beberapa media massa seperti Kompas (2020) tanggal 27 Januari 2020, dan berita di Kaili Post (2020) mewawancarai Kepala Seksi Observasi BMKG Kelas 1 Palu, pada tanggal 28 Januari 2020, menjelaskan bahwa terkait dengan belum di tandatangannya Peta Zona Ruang Rawan Bencana oleh Kepala BMKG, karena ada perbedaan indeks Kerentanan Gempa Bumi (IKG) dengan Zona Rawan Bencana (ZRB).

Selanjutnya berdasarkan hasil observasi dan wawancara kepada pihak pemerintah Provinsi Sulawesi Tengah, diperoleh informasi bahwa dari perencanaan tata ruang yang mendukung peruntukan kawasan-kawasan fungsional adalah rencana tata ruang dalam mengatur struktur dan pola ruang wilayah kota merupakan yang dapat ditentukan sebagai kawasan fungsional, terdiri atas kawasan konservasi, kawasan budidaya, kawasan strategis kota, kawasan permukiman, dan kawasan pertahanan negara. Jika pelaksanaan rencana tata ruang kurang selaras dan terpadu, kurang efektif dan efisien, dan kurang mendukung kawasan fungsional maka akan berimplikasi pada peningkatan risiko bencana. Upaya untuk meminimalkan risiko bencana salah satunya dengan penataan lanskap kota dalam bentuk rencana ruang; rencana aktivitas; rencana fasilitas; rencana sirkulasi; dan rencana vegetasi (Ihsan dan Pramukanto, 2017). Oleh karena itu pemanfaatan ruang yang menunjang mitigasi bencana seperti ketersedian jalur evakuasi, titik berkumpul, elevated shelter, dan penataan ruang terbuka hijau (RTH) serta green barrier harus mendapat perhatian dari pemerintah.

Berdasarkan hasil wawancara dengan narasumber, diperoleh informasi bahwa Rencana Pembangunan Pangkalan di wilayah Korem 132/Tadulako tahun ini sesuai dengan peraturan Panglima TNI yang sudah terbit antara lain meliputi pembangunan:

1. Koramil Watatu di wilayah Kabupaten Donggala, 
2. Koramil Dolo Selatan di wilayah Kabupaten Sigi Biromaru,

3. Kodim Banggai Laut di wilayah Kabupaten Banggai Kepulauan, dan

4. Rencana Pembangunan Korem baru di wilayah Kabupaten Morowali Provinsi Sulawesi Tengah.

Untuk Markas Korem

132/Tadulako, sudah disiapkan lahan baru sesuai dengan perencanaan dari pemerintah daerah tingkat 1 Provinsi Sulawesi Tengah yang akan menjadikan satu komplek perkantoran di Jalan Sambaru, Baru, Desa Besusu Barat, Kecamatan Palu Timur, Kota Palu. Pembangunan Markas Korem ini sesuai dengan perubahan tipe Korem dari tipe B (Kolonel) menjadi tipe A (Brigadir Jenderal). Perubahan susunan tata ruang wilayah perkantoran sebagai pusat pemerintahan ini menurut narasumber dari Korem 132/Tadulako, sebaiknya juga mengatur wilayah pendukungnya yang meliputi wilayah pusat industri, wilayah pusat logistik, wilayah pertanian, dan lain-lain yang mempedomani peta zona ruang rawan bencana. Dari hasil wawancara dengan Kolonel Laut (T) Busro, perwira analis di Dirjen Kuathan Kemhan, dijelaskan bahwa untuk peta ruang rawan bencana di daerah secara spesifik belum tercantum di dalam peraturan-peraturan yang berhubungan dengan rencana tata ruang wilayah pertahanan.

Dari hasil wawancara juga diperoleh keterangan bahwa hingga saat ini belum ada rencana untuk pembangunan kembali dermaga kapal selam di Lanal Palu yang saat ini kondisinya rusak berat. Hal ini juga disampaikan oleh Kapten Laut Tehnik Anang Budi Santoso Selaku Kasat Paslat Lanal Palu Dan Kapten Laut Tehnik Astriyuwono Selaku Pasminlog Lanal Palu tanggal 18 Agustus 2020 di markas Lanal Palu yang mewakili Komandan Lanal Palu sebagai narasumber wawancara, di sampaikan oleh ke dua narasumber bahwa, belum ada informasi tentang pembangunan kembali dermaga kapal selam di Lanal Palu.

Menurut penjelasan dari narasumber di Korem 132/Tadulako, maupun di Lanal Palu, asset pangkalan yang dimiliki antara lain berupa tanah yang di jadikan sebagai markas, maupun pangkalan, sebagian besar melalui proses hibah dari pemerintah, terutama pemerintah daerah. Artinya tanah tersebut sejak semula bukan milik Kemhan/TNI (sejak awal telah masuk dalam rencana umum tata ruang wilayah pertahanan, misalnya sebagai daerah pangkal perlawanan yang 
ditetapkan oleh Kemhan/TNI) tetapi diperoleh dari hibah selanjutnya di urus sertifikatnya menjadi milik Kemhan/TNI.

Berdasarkan hasil wawancara dengan Kasi perencanaan Korem 132/Tadulako Letkol Kav Wahyudi, selanjutnya observasi dan studi dokumen di Korem 132/Tadulako diperoleh informasi tentang rencana pembangunan yang di jabarkan di dalam Rencana Kerja dan Anggaran Kementerian/Lembaga (RKA K/L) Tahun Anggaran 2021. Menurut narasumber dari Korem 132/Tadulako, rencana pembangunan dan pemeliharaan pada RKA tahun anggaran 2021 ini telah di sinkronkan dengan peta zona ruang rawan bencana, terutama untuk tipe bangunan yang akan di bangun atau di perbaiki di sesuaikan dengan daerah rawan gempa seperti di Palu dan sekitarnya. Tetapi apakah nantinya anggaran yang di ajukan sesuai dengan konstruksi tahan gempa, hal tersebut masih perlu di dalami dengan tim pembangunan yang nantinya akan bekerja jika RKA tahun anggaran 2021 dari Korem 132/Tadulako di setujui oleh pimpinan.

Tentang sinkronisasi peta zona ruang rawan bencana Palu dan sekitarnya dengan rencana tata ruang wilayah pertahanan di pangkalan Angkatan Laut
Palu, disampaikan oleh Kapten Laut (T) Anang Budi Santoso Selaku Kasat Paslat Lanal Palu Dan Kapten Laut (T) Astriyuwono Selaku Pasminlog Lanal Palu tanggal 18 Agustus 2020 di markas Lanal Palu yang mewakili Komandan Lanal Palu sebagai narasumber wawancara, bahwa memang belum ada rencana untuk perbaikan di dermaga kapal selam yang saat ini kondisinya masih rusak. Jika nantinya dermaga kapal selam dan fasilitasnya akan diperbaiki, maka di butuhkan dana yang lebih besar karena konstruksinya harus di sesuaikan dengan konstruksi yang tahan terhadap bencana alam gempa bumi dan tsunami, sesuai dengan peta zona ruang rawan bencana Palu dan sekitarnya yang telah di buat, bahwa letak dermaga kapal selam tersebut masuk kedalam zona merah rawan bencana, yang di lintasi oleh patahan Palukoro.

Oleh karena itu, pembangunan kembali pangkalan militer yang telah mengalami kerusakan di Wilayah Palu, Sigi, dan Donggala sebaiknya harus disinkronisasikan dengan Peta Zona Ruang Rawan Bencana, sehingga kerusakan pada fasilitas militer di wilayah Palu, Sigi, dan Donggala yang terjadi akibat bencana alam gempa dan tsunami tidak kembali terulang di masa depan. Hal 
tersebut bisa di lakukan dengan menyesuaikan konstruksi bangunan dengan tipe konstruksi tahan gempa, maupun di pindahkan ke lokasi yang aman sesuai dengan Peta Zona Rawan Bencana.

\section{KESIMPULAN}

Berdasarkan hasil penelitian dan pembahasan yang telah diuraikan pada penelitian ini, maka dapat disimpulkan bahwa Peta Zona Ruang Rawan Bencana untuk wilayah Kota Palu dan sekitarnya telah di buat untuk di pedomani dalam pembangunan di wilayah tersebut. Sehingga untuk rencana tata ruang wilayah pertahanan di wilayah Palu, Sigi, dan Donggala, baik itu perbaikan fasilitas/pangkalan militer yang mengalami kerusakan akibat bencana gempa dan tsunami, maupun pembangunan fasilitas/pangkalan militer yang baru, yang di susun oleh instansi militer di daerah tersebut, atau direncanakan oleh satuan atas, harus berdasarkan pada Peta Zona Ruang Rawan Bencana yang telah ada.

Pembangunan fasilitas pangkalan militer di wilayah rawan bencana seperti di Palu, Sigi dan Donggala harus di evaluasi agar kejadian kerusakan terhadap fasilitas strategis contohnya dermaga kapal selam, kerusakan terhadap kapal perang di Lanal Palu akibat bencana gempa bumi dan tsunami tidak terulang kembali. begitu penting dan strategisnya pertahanan wilayah maka pembinaan wilayah dan tata ruang menjadi faktor penting dalam implemetasi sistem pertahanan negara. Perbaikan fasilitas militer di Kota Palu, Sigi, dan Donggala yang mengalami kerusakan akibat bencana alam, dan sampai dengan saat ini masih belum di perbaiki, sebaiknya mempertimbangkan dan mempedomani penataan wilayah sesuai dengan Peta Zona Ruang Rawan Bencana di Wilayah Palu, Sigi, dan Donggala, sehingga harus di lakukan sinkronisasi antara Rencana Tata Ruang Wilayah Pertahanan dengan Peta Zona Ruang Rawan Bencana di wilayah Palu, Sigi, dan Donggala.

Berdasarkan kesimpulan tersebut, maka peneliti merekomendasikan kepada pemerintah maupun stake holder yang berkepentingan dengan masalah sinkronisasi rencana tata ruang wilayah pertahanan dengan peta zona ruang rawan bencana di Kota Palu dan sekitarnya agar dapat mempertimbangkan:

a. Sinergitas antara TNI dan pemerintah daerah, serta organisasi lainnya yang terlibat harus lebih ditingkatkan untuk mengatasi kendala yang ada, terutama yang menyangkut anggaran 
dan peralatan yang digunakan dalam penanggulangan bencana, dan pembangunan kembali fasilitas yang rusak akibat bencana.

b. Perencanaan dalam pembangunan fasilitas/pangkalan militer terutama yang bernilai strategis, terutama di daerah rawan bencana, harus di sinkronkan dengan peta ruang rawan bencana, sehingga dapat mencegah terganggunya kesiapan Alutsista dalam rangka Pertahanan Negara.

\section{DAFTAR PUSTAKA}

Indonesia. Undang-Undang Republik Indonesia No. 3 tahun 2002 tentang Pertahanan Negara.

Undang-Undang Republik Indonesia No. 26 tahun 2007 tentang Penataan Ruang.

Ali, Yusuf, et al. (2019). Buku Bahan Ajar Manajemen Logistik dan Pengadaan Peralatan Pertahanan. Bogor, Unhan Press.

Creswell, John W. (2010). Research Design: Pendekatan Metode Kualitatif, Kuantitatif, dan Campuran. Edisi Keempat. Yogyakarta: Pustaka Pelajar.

David, Fred R. (2011). Strategic Management. Buku 1. Edisi 12. Jakarta.

Miles, Matthew B.; A. Michael Huberman; dan J. Saldaña. (2014). Qualitative Data Analysis: A Methods Sourcebook. Edition 3. United States of America: SAGE Publications Inc.

NTHMP. (2001). Assessment of the National Tsunami Hazard Mitigation Program. USA.

Pusat Studi Gempa Nasional. (2018). Kajian Gempa Palu Provinsi
Sulawesi Tengah 28 September 2018 (M7.4). Bandung: Pusat Penelitian dan Pengembangan Kementerian PUPR.

Supriyatno, Makmur dan Yusuf Ali. (2018). Pengantar Manajemen Pertahanan. Bogor: Universitas Pertahanan Press.

Suwandiyanto. (2010). Manajemen Strategi dan Kebijakan Perusahaan. Bandung: Alfabeta.

\section{Artikel Jurnal:}

Bellier, Olovier, et. al. (2001). High slip rate for a low seismicity along the Palu-Koro active fault in central Sulawesi (Indonesia). Terra Nova, 13, 463-470.

Edyanto, CB Herman. (2011). Analisa Kebijakan Penataan Ruang Untuk Kawasan Rawan Tsunami Di Wilayah Pesisir. Jurnal Teknik Lingkungan. 12 (3), 309-318.

Minasny, et. Al. (2020). Global soil science research collaboration in the 21st century: Time to end helicopter research. Geoderma. Elsevier.

Harbitz, Carl B., et al. (2006). Mechanisms of tsunami generation by submarine landslides: a short review. Norwegian Journal of Geology/Norsk Geologisk Forening. 86 (3),

Ihsan, Fadhilatul dan Qodarian Pramukanto. (2017). Perencanaan Lanskap Kota Pariaman Provinsi Sumatera Barat Berbasis Mitigasi Tsunami. Jurnal Lanskap Indonesia. 9 (1), 1-12.

Website:

Badan Geologi Kementerian ESDM. (2018). Peta Zona Rawan Bencana Palu dan Sekitarnya diakses dalam https://www.humanitarianresponse.i nfo/en/operations/indonesia/infogra phic/peta-zona-rawan-bencana paludan-sekitarnya pada tanggal 2019.

Build Change. (2019). Central Sulawesi Earthquake and Tsunami 
Reconnaissance Report. Diakses dalam https://buildchange.org/app /uploads/2019/04/2019-02-04-

Central-Sulawesi-Earthquake-and-

Tsunami-Reconnaissance-

Report_External_reduced.pdf pada tanggal 2019

Data Informasi Bencana Indonesia (DIBI). (2019). Diakses dalam https://bnpb.cloud/ pada tanggal 2019.

DetikNews. (2018). Kondisi Pangkalan Angkatan Laut Palu Rusak Parah Usai Tsunami. Diakses dalam https://news.detik.com/berita/d4236072/kondisi-pangkalanangkatan-laut-palu-rusak-parahusai-tsunami pada tanggal 2019.

Kaili Post. (2020). Terbukti BMKG Tak Setuju Peta Zona Rawan Bencana. Diakses dalam https://kailipost.com /2020/01/terbukti-bmkg-tak-setujupeta-zona-rawan-bencana.html pada tanggal 2020.

Kompas. Peta Bencana Palu Abaikan Survei BMKG. Diakses dalam https://kompas.id/baca/humaniora/2 020/01/27/peta-bencana-paluabaikan-survei-bmkg pada tanggal 2020.

Malik, Yakub. (2009). Penentuan Tipologi Kawasan Rawan Gempabumi Untuk Mitigasi Bencana Di Kecamatan Pangalengan Kabupaten Bandung. Diakses dalam https://ejournal.upi.edu/index.php/g ea/article/download/1665/1124 pada tanggal 2019. 